DOI: 10.20472/IAC.2019.049.016

\title{
SILVIA GOLEM
}

Faculty of Economics, University of Split, Croatia

\section{DIFFERENT APPROACHES AND MEASURES OF FISCAL DECENTRALISATION}

\begin{abstract}
:
Once the phenomenon of fiscal decentralisation was appropriately operationalised and measured, it has become evident that not many countries had absolutely self-financing sub-national governments. The evidence shows that, in many developed countries, fiscal decentralisation has occurred almost exclusively through devolution of expenditure activities, while a large part of the regional and local government expenditures is funded primarily by intergovernmental grants, revenue-sharing programs, or other centrally controlled funds. Measurement-wise, this suggests that taxes should be refined in terms of the degree of autonomy they provide to sub-national governments. In the relevant empirical studies, it is a common practice to use accounting measures of either revenue or spending shares for sub-national relative to general government as a proxy for fiscal decentralisation. However, those two accounting measures may not capture accurately the phenomenon of fiscal decentralisation. The two standard sources of data for fiscal decentralisation have been the IMF's Government Finance Statistics (GFS) where the intergovernmental fiscal structure of countries is not captured properly and OECD's measure of revenue decentralisation where taxes are classified in terms of the degree of autonomy they provide to sub-national governments. As an improved measure of revenue decentralisation, Stegarescu (2005) constructs an appropriate measure of fiscal decentralisation; namely, "purified" sub-national own-source revenues as a share of total government revenues. The main aim of this paper is to compare in details the above mentioned measures of fiscal decentralisation, and evaluate the bias in the accounting measures compared to a "purified" measure that accounts for the real fiscal autonomy of sub-national governments by comparing the results gained through estimation of the government sector size model using the pooled mean group (PMG) estimation approach.
\end{abstract}

\section{Keywords:}

fiscal decentralisation, fiscal structure, own-source sub-national revenues, PMG estimation

JEL Classification: H0O, H77, H79 